\title{
Preventable In-Hospital Cardiac Arrests- Are We Monitoring the Wrong Organ?
}

\author{
Lakshmipathi Chelluri \\ University of Pittsburgh School of Medicine, Pittsburgh, USA \\ Email: chelluril@upmc.edu
}

Received 6 June 2014; revised 16 July 2014; accepted 16 August 2014

Copyright @ 2014 by author and Scientific Research Publishing Inc.

This work is licensed under the Creative Commons Attribution International License (CC BY). http://creativecommons.org/licenses/by/4.0/

(c) (i) Open Access

\begin{abstract}
Pulseless Electrical Activity (PEA) and aystole are the most common initial rhythms in patients with in-hospital cardiac arrest. Respiratory failure is the most common cause for Rapid Response Team alert, and may be the initial cause for in-hospital cardiac arrests. Although cardiac monitoring is shown to be ineffective in identifying patients at risk for cardiac arrest, it is the most common monitoring used on the wards. As many of the cardiac arrests may have a respiratory origin, respiratory monitoring could identify patients at risk to develop cardiac arrest. Reclassifying cardiac arrests as primary cardiac and secondary would help in identifying secondary causes, and monitoring that could help in early identification of deterioration.
\end{abstract}

\section{Keywords}

\section{Cardiac Arrest, Respiratory, Monitoring}

The initial rhythm observed in many patients suffering cardiac arrest (CA) in the hospital is either asystole or Pulseless Electrical Activity (PEA) with classic ventricular fibrillation/ventricular tachycardia (VF/VT) in a much smaller group of CA patients [1] [2]. The etiology of the initial rhythm is probably different between patients with primary cardiac disease (ischemia/failure) causing VF/VT, and secondary non-cardiac events (e.g., hypoxia, respiratory failure) causing asystole/PEA. Since many in-hospitals CA are secondary to non cardiac events, separating these events into primary and secondary etiologies would be useful because the monitoring needed to prevent these two causes of CA could be different.

The most common monitoring used outside the intensive care unit (ICU) is electrocardiography (ECG). But the utility of ECG to prevent secondary CA is not known. Although ECG monitoring should be limited to patients with cardiac disease, many patients receive ECG monitoring unnecessarily [3] [4]. Henriques-Forsythe et al. reviewed published literature on telemetry use, and concluded that telemetry infrequently resulted in signifi- 
cant changes in clinical management but increased unnecessary testing and costs [3]. Efficient use of resources is a concern in view of increasing health care costs, and requires reexamination of practices which do not contribute to improved outcomes.

Secondary CA is often related to hypoxia or fatigue/hypercarbia leading to respiratory compromise followed by tachycardia, bradycardia and CA. Respiratory compromise is a frequent cause for Rapid Response Team activation, and Delgado et al. reported that respiratory problems were the leading cause for admissions to ICU within 24 hours of admission to the ward [5]. The current monitoring systems available for prevention of secondary CA include ECG (not effective), pulse oximetry, early warning systems for Rapid Response Teams, commercial multi modality monitoring systems, and End Tidal $\mathrm{CO}_{2}\left(\mathrm{ETCO}_{2}\right)$ monitoring. Each of these has limitations but Pulse oximetry and $\mathrm{ETCO}_{2}$ probably are the most effective in identifying respiratory compromise early, and prevent secondary CA. Although respiratory rate is a good indicator of respiratory compromise, the documented respiratory rate in the medical record may be the most inaccurate of the recorded vital signs [6] [7]. Hospital monitoring practices need to be reevaluated with regard to use of pulse oximetry to maximize its efficiency and understand its limitations [8]. Although there are few data to support maintenance of $\mathrm{SaO}_{2}$ of $>92 \%$

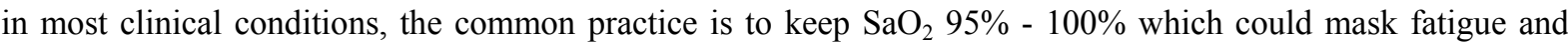
raising $\mathrm{PaCO}_{2}$. A change in practice to keep $\mathrm{SaO}_{2} \sim 92 \%$ and lower alarm limit at $80 \%-85 \%$ may increase sensitivity of staff to decreases in $\mathrm{SaO}_{2}$, and decrease the number of false alarms [9]. The multimodality monitoring systems which include vital signs and pulse oximetry are useful and can operate off existing hospitals electronic medical records. They need to be evaluated with regard to their cost effectiveness, and may not need significant additional resources for implementation. $\mathrm{ETCO}_{2}$ monitoring is a useful tool and may be better than existing monitoring tools, but the technology needs improvement so that it can be used for prolonged periods in the non operative setting. Trials focusing on specific high risk patients (e.g. patients with obesity hypoventilation syndrome, sleep apnea, patients receiving analgesics/sedatives, and patients on the wards with tracheostomy) at risk to develop respiratory compromise would help in identifying patients that would benefit from respiratory monitoring.

A change in paradigm of the etiology of CA into primary and secondary would lead to more focused efforts to identify causes and prevention of secondary CA. The impact of respiratory monitoring on prevention secondary cardiac arrests needs to be evaluated. Reallocating resources from ECG monitoring to appropriate use of respiratory monitoring (pulse oximetry, multimodality analysis and developing technologies to monitor $\mathrm{ETCO}_{2}$ ) may decrease secondary CA without increasing costs.

\section{References}

[1] Girota, S., Nalamothu, B.K., Spertus, J.A., Li, Y., Krumholz, H.M. and Chan, P.S. (2012) Trends in Survival after InHospital Cardiac Arrest. The New England Journal of Medicine, 367, 1912-1920. http://dx.doi.org/10.1056/NEJMoa1109148

[2] Chen, L.M., Nallamothu, B.K., Spertus, J.A., Li, Y. and Chan, P.S. (2013) Association between a Hospital's Rate of Cardiac Arrest Incidence and Cardiac Arrest Survival. JAMA Internal Medicine, 173, 1186-1194. http://dx.doi.org/10.1001/jamainternmed.2013.1026

[3] Henriques-Forsythe, M.N., Ivonye, C.C., Jamched, U., Kamuguisha, L.S.K., Olejme, K.A. and Onwuanyi, A.E. (2009) Is Telemetry Overused? Is It as Helpful as Thought? Cleveland Clinic Journal of Medicine, 76, 368-372. http://dx.doi.org/10.3949/ccjm.76a.07260

[4] Schull, M.J. and Redelmeier, D.A. (2000) Continuous Electrocardiographic Monitoring and Cardiac Arrest Outcomes in 8,932 Telemetry Ward Patients. Academic Emergency Medicine, 7, 647-652. http://dx.doi.org/10.1111/j.1553-2712.2000.tb02038.x

[5] Delgado, M.K., Liu, V., Pines, J.M., Kipnis, P., Gardner, M.N. and Escobar, G.J. (2013) Risk Factors for Unplanned Transfer to Intensive Care within 24 Hours of Admission from the Emergency Department in an Integrated Healthcare System. Journal of Hospital Medicine, 8, 13-19. http://dx.doi.org/10.1002/jhm.1979

[6] Cretikos, M.A., Bellomo, R., Hillman, K., Chen, J., Simon, F. and Flabouris, A. (2008) Respiratory Rate: The Neglected Vital Sign. Medical Journal of Australia, 188, 657-659.

[7] Semler, M.W., Stover, D.G., Copland, A.P., Hong, G., Johnson, M.J., Kriss, M.S., Otepka, H., Wang, L., Christman, B.W. and Rice, T.W. (2013) Flash Mob Research: A Single Day, Multicenter, Resident-Directed Study of Respiratory Rate. Chest, 143, 1740-1744. 
[8] Fu, E.S., Downs, J.B., Schweiger, J.W., Miguel, R.V. and Smith, R.A. (2004) Supplemental Oxygen Impairs Detection of Hypoventilation by Pulse Oximetry. Chest, 126, 1552-1558. http://dx.doi.org/10.1378/chest.126.5.1552

[9] Taenzer, A.H., Pyke, J.B., McGrath, S.P. and Blike, G.T. (2010) Impact of Pulse Oximetry Surveillance on Rescue Events and Intensive Care Unit Transfers. A Before-and-After Concurrence Study. Anesthesiology, 112, $282-287$. http://dx.doi.org/10.1097/ALN.0b013e3181ca7a9b 
Scientific Research Publishing (SCIRP) is one of the largest Open Access journal publishers. It is currently publishing more than 200 open access, online, peer-reviewed journals covering a wide range of academic disciplines. SCIRP serves the worldwide academic communities and contributes to the progress and application of science with its publication.

Other selected journals from SCIRP are listed as below. Submit your manuscript to us via either submit@scirp.org or Online Submission Portal.
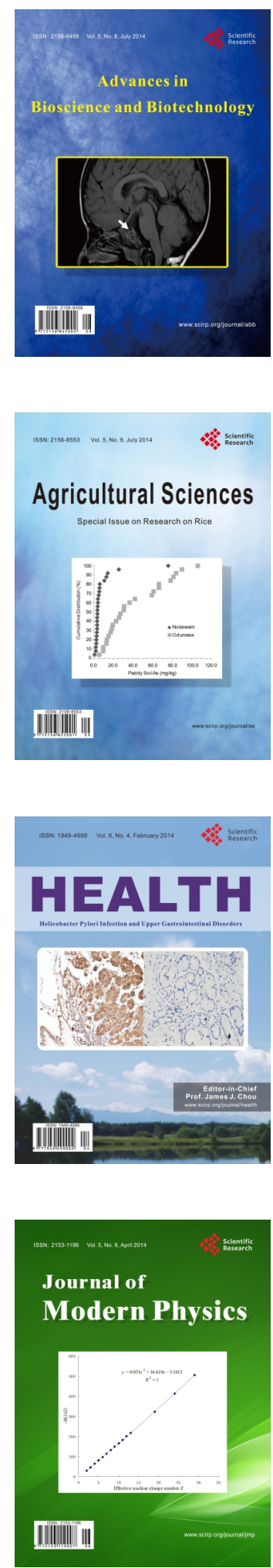
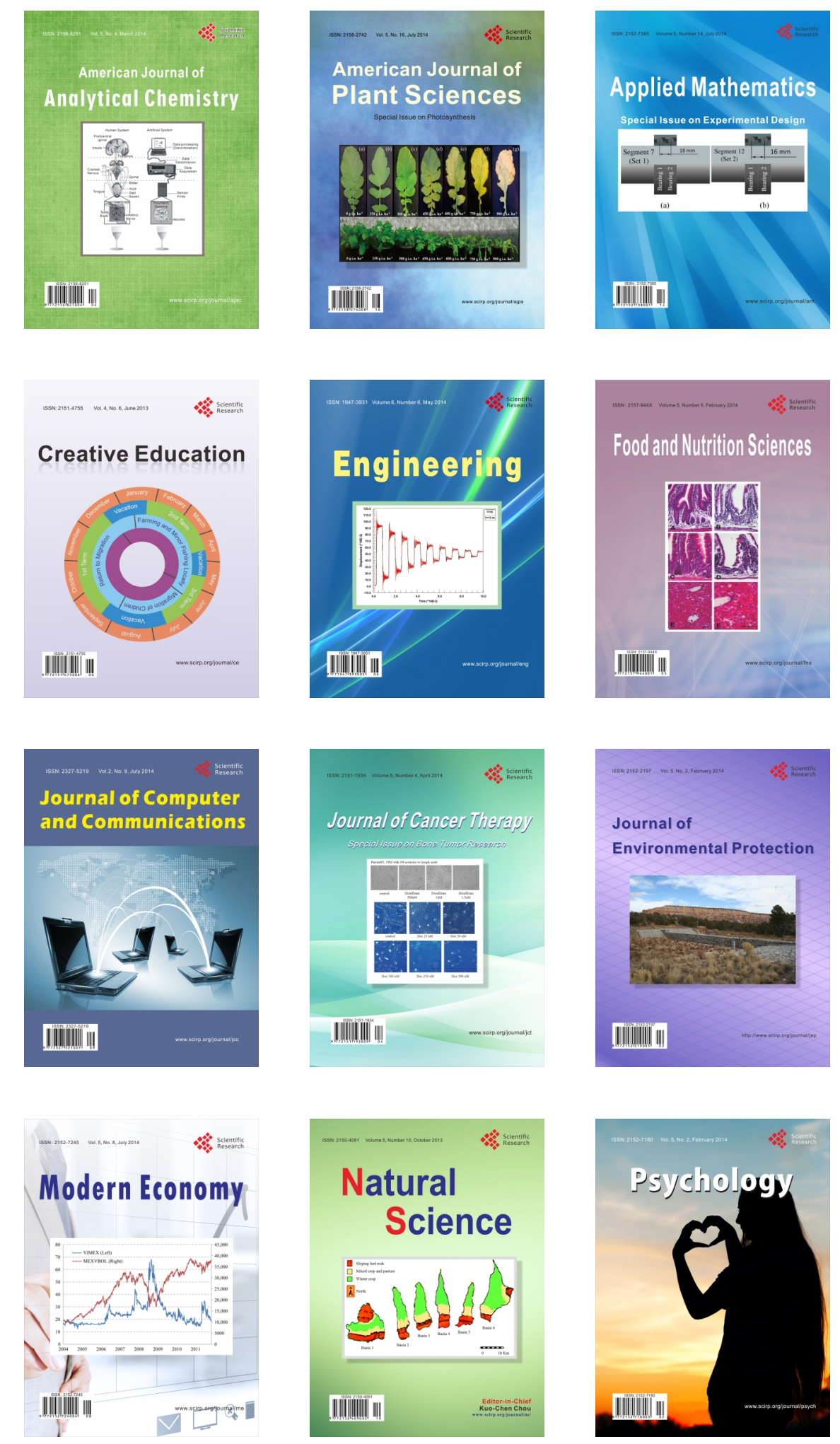